\title{
Development of CFT Column Reinforcement Method to Improve Seismic Performance of Buildings
}

\author{
Dong-Oun Lee \\ Department of Architectural and Civil Engineering, Dongseo University, Busan, Republic of Korea
}

\begin{abstract}
Recently, earthquake-affected areas are increasing worldwide. Especially, buildings that are not designed to be earthquake resistant may be vulnerable to earthquakes and various reinforcement methods are being applied to improve seismic performance. In addition, structures that penetrate buildings such as roads and subways also need to be reinforced by vibrations such as earthquakes. This this research, therefore, aims to develop CFT column strengthening method with excellent seismic performance, so that, there is no damage caused by collapse in buildings where periodic vibration and earthquake occur. The seismic retrofit method of the CFT (Concrete Filled Tube) columns is a method in which CFT connectors are installed on the surface of a conventional reinforced concrete member first then the CFT columns are welded and integrated into the joint device, finally, high-performance mortar is injected to improve the seismic performance of existing reinforced concrete. For the performance test, we propose structural simulation and excess water removal method to improve the concrete performance inside the CFT column.
\end{abstract}

Key words: $\mathrm{CFT}$ column, seismic performance, earthquake resistant, high-performance mortar, structural simulation, performance

\section{INTRODUCTION}

The number of earthquakes in Korea has risen steadily from an annual average of 40 times, since, 2000 to 60 times after 2009 (the National Emergency Management Agency). Figure 1 is a graph showing the earthquake occurrence and it can be seen that the recent frequency of occurrence rapidly increases compared to other areas. In addition, due to the earthquake of magnitude 2.3 or more, large-scale damage has occurred in Korea area, so, it is necessary for buildings to cope with the earthquake in various ways. Among the countermeasures against such earthquakes, the seismic performance improvement of columns which are the main members of buildings should be reviewed first to prevent safety accidents. Seismic performance of aged facilities is expected to cause massive damage in the event of an earthquake (Hong et al., 2013; Kwon et al., 2005; Eom and Shin, 2011; Lee, 2013; Jang, 2011).

Therefore, seismic retrofit of aged buildings should be done at the same time with seismic design of newly constructed buildings. In particular, the quality of the column members which play an important role in the occurrence of the earthquake is of utmost importance.

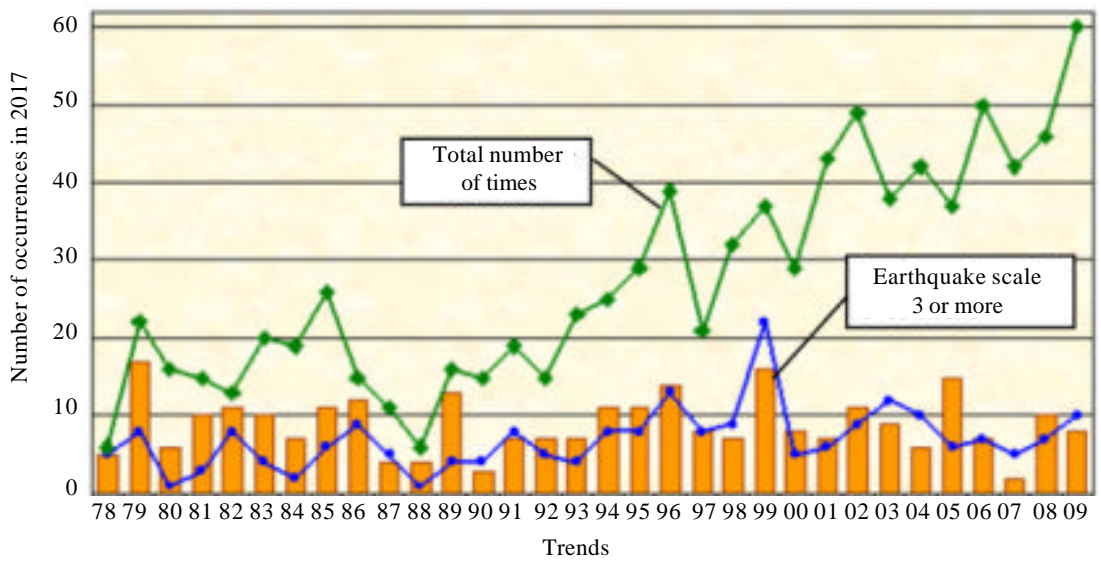

Fig. 1: Earthquake occurrence trends in Korea 
That is seismic performance and constructability are required for reinforcement of new and old buildings.

Figure 1 shows the destruction of the column structure due to the earthquake. It also shows how this leads to the collapse of the entire building.

As the demand for large-scale factories and high-rise buildings has increased recently, the importance of maximizing the interior space and managing the economical construction has been emphasized (Fig. 2).

Thus, the design of Concrete-Filled in Tube (here in after referred to as CFT) structure columns that are strong against axial force, lateral force and fire-resistance is increasing (Fig. 1). The CFT column is a structural system that the concrete is filled in the steel pipe with rigidity and that exhibits excellent performance in terms of the increase in the strength of the concrete filled by the constraining effect of the steel pipe and the increase of the workability and the member strength due to the local buckling reinforcement effect.

However, since, the outer surface of the column is piled up by the steel pipe, the amount of bleeding water of the concrete to be filled is concentrated at the upper portion and the upper joint portion which is the main structure, of the column becomes weak. And excessive internal excess water may be vulnerable to spalling due to increased internal water vapor pressure in the event of a fire (Lee et al., 2012; Jung et al., 2014; Lee, 2013; Shin and Kim, 2005).

Korean Ministry of Land, Infrastructure and Transport has stipulated that fire resistance performance of $3 \mathrm{~h}$ should be ensured for columns of high-rise buildings exceeding 12 floors for all buildings, based on the fire resistance performance criteria in the "Accreditation and management standards for fireresistance structures". In other words, CFT columns with high axial ratio can be applied to structures with fire resistance of $<2 \mathrm{~h}$ in medium and low-rise buildings but it is difficult to satisfy the required $3 \mathrm{~h}$ fire resistance performance in high-rise buildings. Further, to satisfy the fire resistance performance of the existing CFT method, those methods of expensive spray coating, refractory of the column but they have disadvantages such as complicated construction and uneconomical. Therefore,

(a)

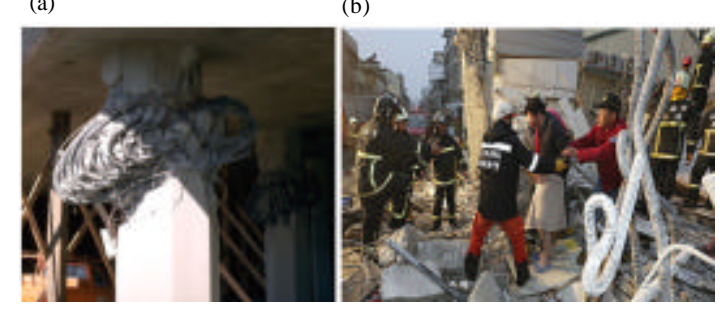

Fig. 2: a, b) Pillar structure destruction due to earthquake coating and board coating are applied to the outer surface there is a need for a new CFT system which can satisfy the refractory performance without expensive refractory cladding and can secure the quality of the upper joining portion of the column by controlling the number of bleeding and internal excess water of the filled concrete.

Therefore, in this study, redundant water of concrete can be discharged early by using paper-drain in the structure of Concrete Filled Steel Tube (CFT). Through this, the durability of the concrete can be increased by tightening the structure. Also, it is possible to remove the bleeding water gathering on the upper part of the column when concrete is poured. This plays an important role in improving the quality performance of the column joint structure which is a disadvantage of the concrete filled steel tube (Kim and Lee, 2015; Alostaz and Schneider, 1996; Kim and Cho, 2009; Jeong et al., 2009; Hyo-Jeong, 2017; Yoon and Joon, 2017; Choi, 2017; Kim and Jung, 2017; Jong-Kook et al., 2017; Yun, 2016).

\section{MATERIALS AND METHODS}

Seismic performance improvement method through CFT convergence technology

Seismic performance improvement using CFT: This study is to develop an innovative method by technology on the CFT column which is a member of the old building (Fig. 3).

Through this, we intend to improve the constructability and structural performance that can be developed into the future technology of stable building structure

In addition, the earthquake-resistant seismic performance improvement can be applied to structures with large amount of vibrations in multidimensional city (to be constructed through road and architecture technology) that are planned to be revised in 2018 and planned to be implemented in 2019. Such a composite multidimensional city requires durable column systems

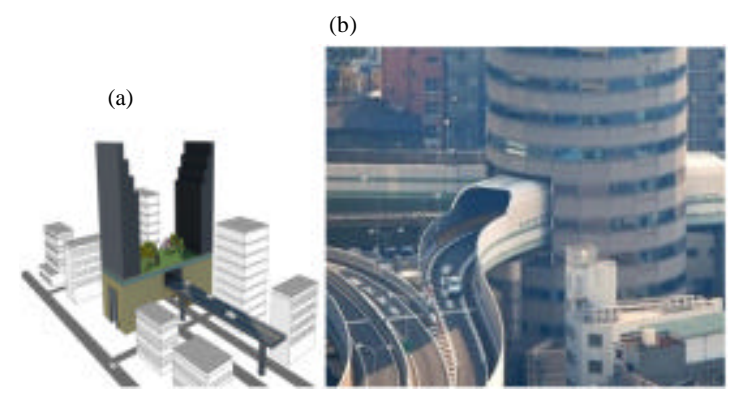

Fig. 3: a, b) Design proposed by Ministry of Land Transport and Transport (left), Osaka TKP building (right) 

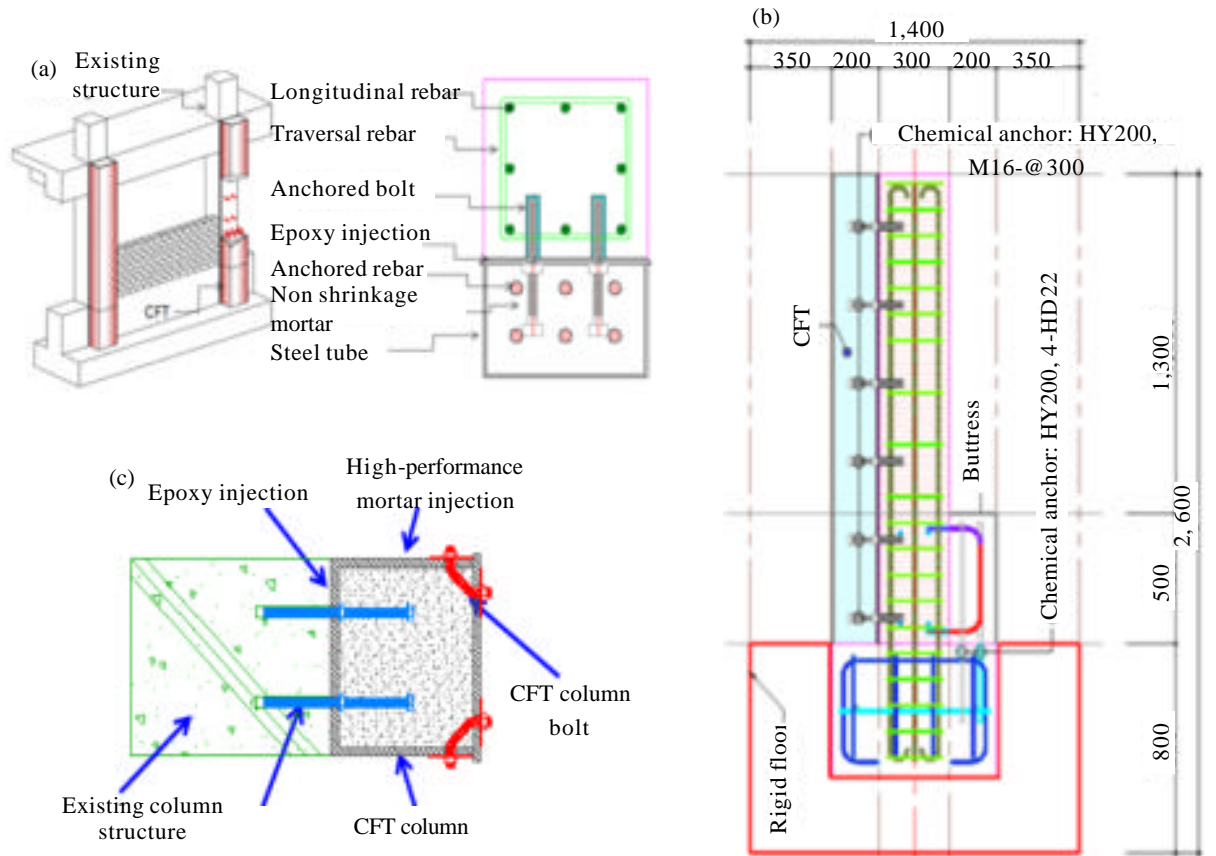

Fig. 4: a-c) Seismic retrofit method by CFT column construction on existing building columns
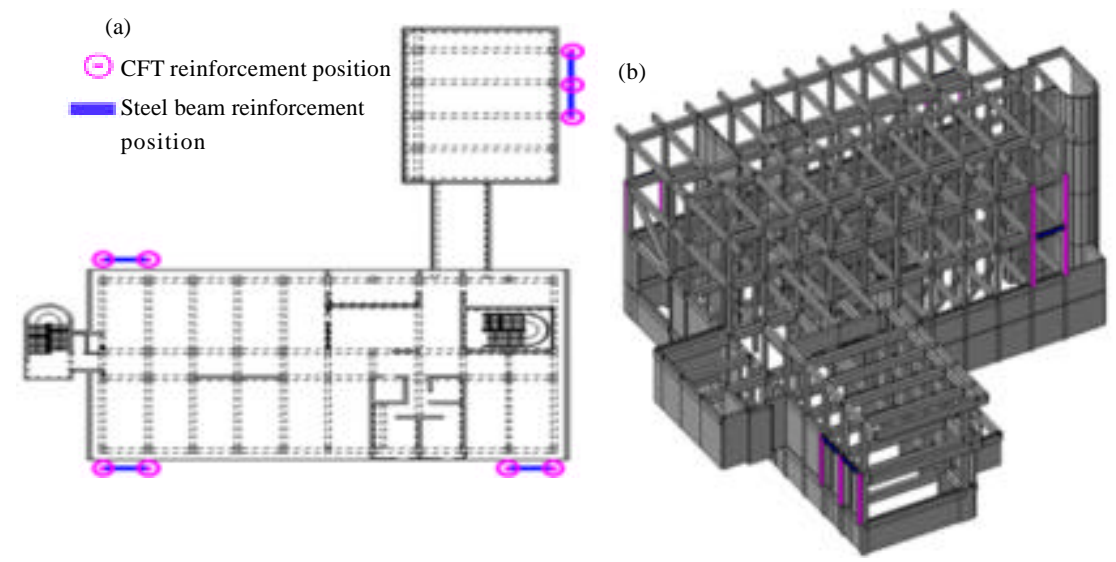

Fig. 5: a, b) Non-linear static analysis results before reinforcement

that can withstand a wide gap due to the strong vibration caused by the passage through the center of the building. In this respect, the Concrete Filled steel pipe (CFT) structure is an excellent confined member type having a high strength due to the concrete confining effect with the steel pipe and the local buckling suppression effect by the filled concrete. It is a column system that combines the material properties of concrete with the material properties of iron efficiently (Young et al., 2016; Lee-Yong, 2016; Kumar, 2015; Pudjisuryadi et al., 2014; Ganiron, 2014a, b).

Concrete is very strong in compressive strength but weak in tensile strength. Iron is strong both in tensile and compressive strength but weak in local buckling. A typical example of a structural system that is complemented by the advantages and disadvantages of these two materials is a reinforced concrete structure and a further improved system is the CFT column system.

Development of CFT seismic reinforcement system for existing buildings: As shown in Fig. 4, it is possible to reinforce seismic performance by connecting CFT columns to existing building columns. CFT column seismic reinforcement method can improve resisting capacity for vertical loads and buckling at the top. In case of aged building, seismic strengthening performance can be improved through high performance mortar and column connector as shown in Fig. 4.

\section{Structural simulation of CFT column reinforcement in} buildings: As shown in Fig. 5, structural simulations were examined by reinforcing the CFT columns with four 

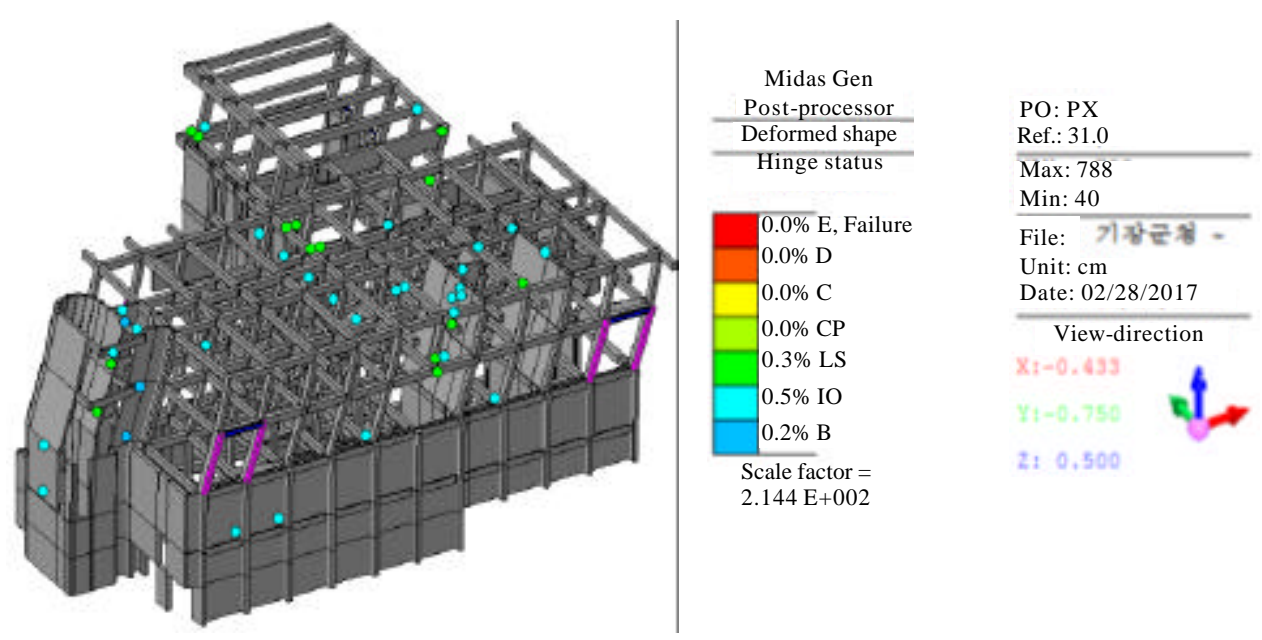

2: 0,500

Fig. 6: Simulated result of plastic hinge condition
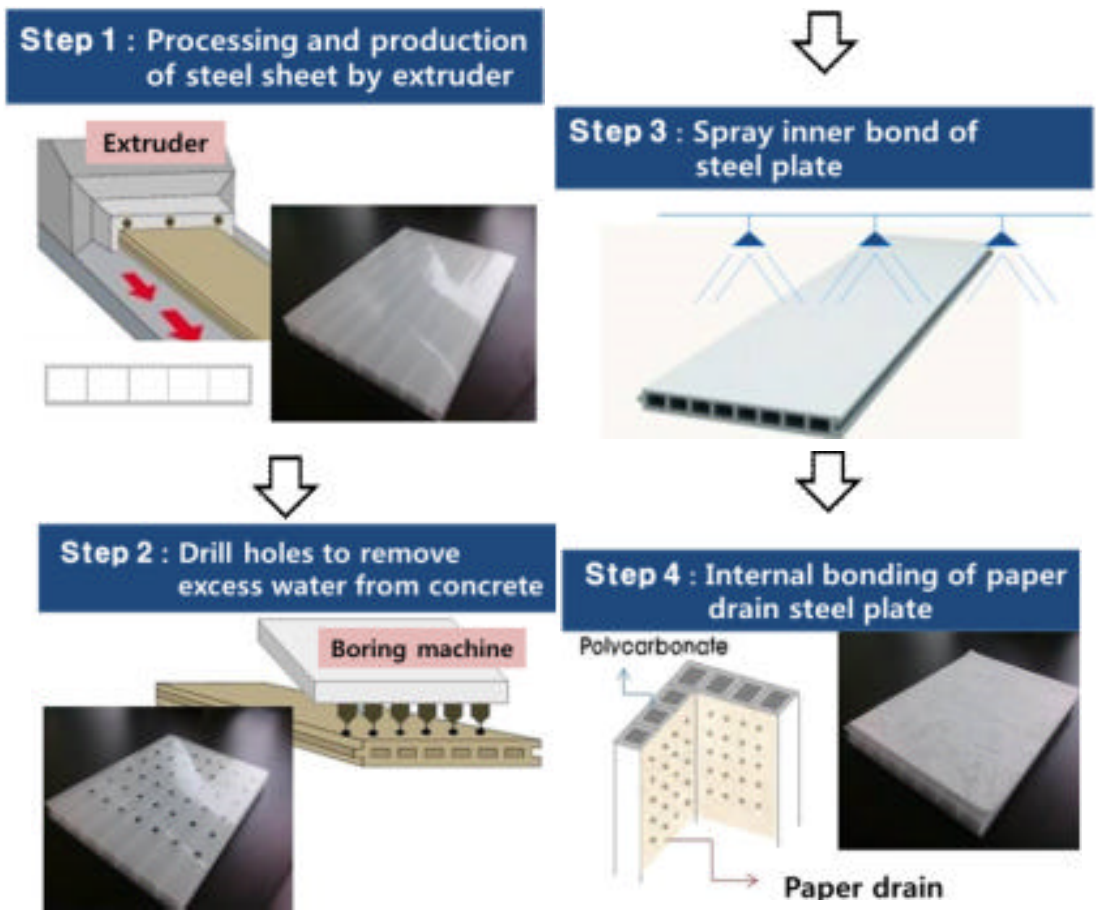

Fig. 7: Paper-drain production process

structures for existing structures. As shown in Fig. 6, the simulated result shows that the result of plastic hinge condition improves the resistance against horizontal displacement (earthquake and vibration) by improving the interlayer deformation angle by $16 \%$ compared to existing buildings.

\section{Paper-drain manufacturing of CFT system Paper-drain production process: Paper drain manufacturing achieves the goal of durability improvement by reducing the bleeding phenomenon by inserting a plastic polycarbonate material.}

As shown in Fig. 7, paper-drain production process is first, attach the paper-drain to each of the four sides of the CFT column before assembling the steel pipe with a strong adhesive, then after the steel pipe assembly is completed, perforated the upper, middle and lower parts of the paper-drain position. After the concrete is poured into the completed steel pipe column, the excess water is discharged through the perforated hole.

This improves the strength of concrete and the denseness of internal structure by reducing the internal 


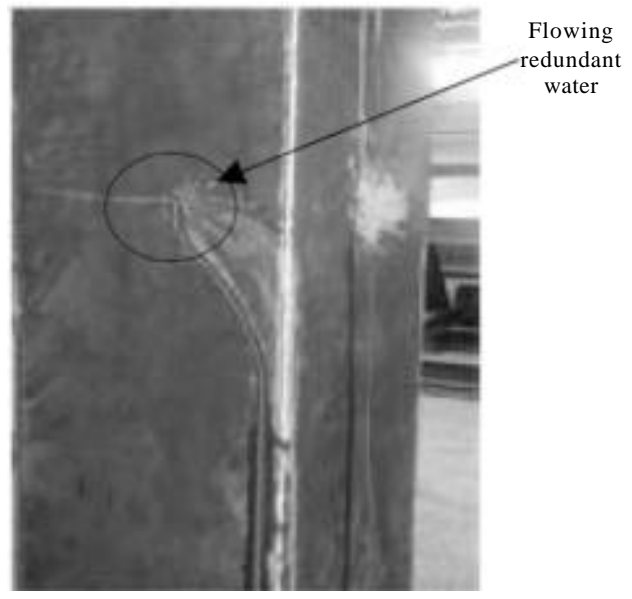

Fig. 8: Discharge excess water through the CFT column

Table 1: Experiment plan

\begin{tabular}{ll}
\hline Items & Levels \\
\hline Mixture & \\
Ready mixed concrete & $20-40-550$ \\
Application of paper-drain & Apply, not apply \\
Experiment & \\
Fresh concrete & Slump, air contents, temperature \\
Hardened concrete & A fire-resistance test (KS F 2257-1) \\
\hline
\end{tabular}

excess water other than the water used in the hydration reaction, so that, it can solve the vulnerability of the upper joining portion of the existing CFT column.

As shown in Fig. 8, concrete can be removed by pouring concrete through the produced CFT column and pouring excess water through the paper drain. Figure 8 is an experiment to examine whether excess water can be discharged through the actual CFT column. Experimental results show that excess water other than water required for concrete hydration can be sufficiently removed.

Fire resistance performance test of CFT column: For the test, $40 \mathrm{MPa}$ degree concrete piece was designed and installed as shown in Table 1 for the preparation of CFT column specimens. In this study, we investigated the effect of paper-drain on the cracking of the upper joint due to bleeding of CFT filled concrete and the occurrence of spalling due to excessive internal excess water. As the measurement items, it was planned to measure the slump, the air amount and the concrete temperature in the unconfined concrete and in the case of hardened concrete, it was planned to measure the temperature history of the column member for the fire resistance test.

\section{RESULTS AND DISCUSSION}

Fire resistance performance test result and concrete micro analysis: Figure 9 shows the appearance of CFT after $180 \mathrm{~min}$ of fire resistance test. Experimental results

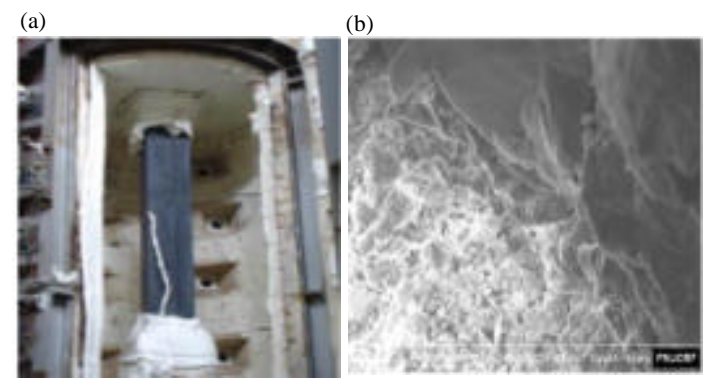

Fig. 9: a, b) CFT test object and concrete structure after $3 \mathrm{~h}$ of fire resistance test

showed that the displacement of the refractory column was $25 \mathrm{~mm}$ and it satisfied the allowable maximum displacement of $40 \mathrm{~mm}$ or less. Also, there was no spalling and buckling during the fire resistance test. Analysis of the microstructure of concrete using PE-SEM revealed that the internal structure was compact and the pore was small (Ganiron, 2014a, b; Ogunkah and Yang, 2014; Kusuma et al., 2015; Astawa et al., 2015; Myeong-Jin et al., 2015; Kusuma and Suprobo, 2012).

\section{CONCLUSION}

This study proposes a CFT column system to improve seismic performance existing buildings. This method can be transformed into an innovative method by combining IT convergence technology. In addition, constructability and structural performance can be improved to create a structure that is sufficiently resistant to earthquakes. Also, the multi-dimensional city is required to have a durable column system capable of withstanding a wide gap due to strong vibration caused by the penetrating road. Therefore, we will develop a CFT column that efficiently responds to the earthquake and vibration of buildings and ensures durable quality.

The CFT system which is a tube structure filled with high strength concrete has excellent performance in various structural performance such as rigidity, stress and composite structure and fire resistance. However, there is a disadvantage that because outer surface of the steel pipe is piled up by the steel pipe, the concrete excess bleeding water is concentrated on the upper part, so that, the joining portion of the column is weakened. However, it is possible to increase the durability of the concrete by making a system-paper-drain is attached to the inner side of the CFT system and holes are drilled in the upper, middle and lower parts from the outside to remove excess water immediately after concrete pouring to remove the bleeding water except the water required for the hydration reaction of the concrete. 


\section{ACKNOWLEDGEMENTS}

This research was supported by Basic Science Research Program through the National Research Foundation of Korea (NRF) funded by the Ministry of Education, Science and Technology (NRF-2017 R1D1A3B05030876). The res earcher resides in 57, Yein-gil, Habuk-myeon, Yangsan-si, Gyeongsangnam-do, Republic of Korea.

\section{REFERENCES}

Alostaz, Y.M. and S.P. Schneider, 1996. Analytical behavior of connections to concrete-filled steel tubes. J. Constr. Steel Res., 40: 95-127.

Astawa, IM.D., Tavio and I.G.P. Raka, 2015. Behavior of partially-prestressed concrete interior beam-column joints for highly-seismic zones. Intl. J. ICT. Aided Archit. Civ. Eng., 2: 1-12.

Choi, H., 2017. [Limitation rainfall runoff in the watershed forest (In Korea)]. Asia Pac. J. Multimedia Serv. Convergent Art Humanities Sociology, 7: 943-952.

Eom, J.U. and T.S. Shin, 2011. A development of interface module between structural design and detail design based on BIM. J. Korean Soc. Steel Constr., 23: 113-124.

Ganiron, J.T.U., 2014b. An empirical investigation on end-users' acceptance of compressed lahar sediment blocks as wall panel. Intl. J. ICT Aided Archit. Civ. Eng., 1: 19-30.

Ganiron, J.T.U., 2014a. The effect of waste glass bottles as an alternative coarse aggregate in concrete mixture. Intl. J. ICT. Aided Archit. Civ. Eng., 1: 1-10.

Hong, S.B., W.J. Kim and H.G. Park, 2013. Development and application of CFT without fire protection using high performance steel and concrete. J. Korea Inst. Build. Constr., 13: 272-281.

Hyo-Jeong, K., 2017. [A study on mobile service design to encourage people in their $20 \mathrm{~s}$ to participate in elections (In Korean)]. Asia Pac. J. Multimedia Serv. Convergent Art Humanities Sociology, 7: 923-934.

Jang, J.W., 2011. Development of rebar placement system of R.C foundation using lean design technique based on structural BIM (SBIM). Master Thesis, Department of Architecture Environmental Engineering, Hanyang University, Seoul, South Korea.

Jeong, Y.S., C.M. Eastman, R. Sacks and I. Kaner, 2009. Benchmark tests for BIM data exchanges of precast concrete. Autom. Constr., 18: 469-484.
Jong-Kook, L., H. So-Jeong and K. Hyo-Eun, 2017. [Augmented CM model in the construction management (In Korean)]. Asia Pac. J. Multimedia Serv. Convergent Art Humanities Sociology, 7: 389399.

Jung, J.H., J.C. Lee and C.K. Kim, 2014. Representation of the shape and layout of rebars using IFC at construction document phase. J. Archit. Inst. Korea Struct. Constr., 30: 31-38.

Kim, K.H. and M.J. Lee, 2015. Structural behavior of beamto-column connections of rectangular CFT structures having different diaphragm opening. J. Korean Soc. Steel Constr., 27: 289-298.

Kim, M.G. and K.Y. Jung, 2017. [Application of UAV photogrammetry for standardization of shoreline survey (In Korean)]. Asia Pac. J. Multimedia Serv. Convergent Art Humanities Sociology, 7: 953-960.

Kim, Y.R. and Y.S. Cho, 2009. The study on application of Korean BIM process in the structural design phase based on a case study. J. Archit. Inst. Korea, 25: 1926.

Kumar, V.U., 2015. An AES architecture with minimum area cost at higher throughput rates. Intl. J. Secur. Technol. Smart Dev., 2: 1-8.

Kusuma, B. and P. Suprobo, 2012. Experimental behavior of concrete columns confined by welded wire fabric as transverse reinforcement under axial compression. ACI. Struct. J., 109: 339-347.

Kusuma, B., Tavio and P. Suprobo, 2015. Behavior of concentrically loaded welded wire fabric reinforced concrete columns with varying reinforcement grids and ratios. Intl. J. ICT. Aided Archit. Civ. Eng., 2: 114.

Kwon, S.H., T.H. Kim, Y.Y. Kim and J.K. Kim, 2005. Longterm behavior of square CFT columns with diaphragm. J. Korea Concr. Inst., 17: 1025-1032.

Lee, J.C., 2013. Information delivery requirements of steel structure according the structural design stages using IDM. J. Korea Acad. Ind. Cooperation Soc., 14: 1467-1473.

Lee, J.C., J.H. Jung, C.K. Kim, J.H. Kim and M.S. Kim, 2012. Representation of standard steel connections using IFC. J. Archit. Inst. Korea Struct. Constr., 28: 65-72.

Lee-Yong, S., 2016. [A study of on the revitalization of urban environment improvement project for the urban regeneration in Eunhaeng 1 district Daejeon (In Korean)]. Asia Pac. J. Multimedia Serv. Convergent Art Humanities Sociology, 6: 445452 . 
Myeong-Jin, K., J. Hung-Chan, C. Kyun-Hyong and C. Doo-Sung, 2015. A study on carbon emission at apartment housing dismantlement and disuse phase in Korea. Intl. J. ICT. Aided Archit. Civ. Eng., 2: $21-28$.

Ogunkah, I.C.B. and J. Yang, 2014. Validation of a multicriteria decision support system for Low-cost green building materials and components. Intl. J. ICT. Aided Archit. Civ. Eng., 1: 11-32.

Pudjisuryadi, P., Tavio and P. Suprobo, 2014. Analytical confining model of square reinforced concrete columns using external steel collars. Intl. J. ICT. Aided Archit. Civ. Eng., 1: 1-18.

Shin, K.J. and H.S. Kim, 2005. Analysis of CFT Beam-tocolumn connections with T-stiffeners. J. Korean Soc. Steel Constr., 17: 375-384.
Yoon, T.B. and K.P. Joon, 2017. [Development of android application for surveying results management of urban facility (In Korean)]. Asia Pac. J. Multimedia Serv. Convergent Art Humanities Sociology, 7: 935-942.

Young, J.P., Y. Chang-Geon and S.M. Lee, 2016. [Development of landslide risk estimation method in urban slope (In Korean)]. Asia Pac. J. Multimedia Serv. Convergent Art Humanities Sociology, 6: 593602.

Yun, H.J., 2016. [A model for urban regeneration by constructing contemporary publicness (In Korean)]. Asia Pac. J. Multimedia Serv. Convergent Art Humanities Sociology, 6: 657666. 